Journal of Animal and Veterinary Advances 9 (17): 2214-2219, 2010

ISSN: $1680-5593$

(C) Medwell Journals, 2010

\title{
Increased Expression of a Reporter Plasmid by Crotalid Venom Fraction
}

\author{
${ }^{1}$ Arcelia Alvarado Islas, ${ }^{2}$ Angel Horacio Sandoval Trujillo, ${ }^{1}$ Victor R. Tenorio Gutierrez, \\ ${ }^{3}$ Rogelio Alonso Morales, ${ }^{1}$ Octavio de Paz Villafan and ${ }^{4}$ Alvaro Aguilar Setien \\ ${ }^{1}$ Departamento de Epizootiologia del Centro Nacional de Investigaciones Disciplinarias en Microbiologia, \\ Instituto Nacional de Investigaciones Forestales, Agricolas y Pecuarias, \\ SAGARPA, Km 15.5, Carretera Mexico-Toluca, Col. Palo Alto, 05110, Mexico, DF \\ ${ }^{2}$ Division de Posgrado en Ciencias Biologicas de la Universidad Autonoma Metropolitana-Xochimilco, \\ Calzada del Hueso 1100, Edificio A, $2^{\circ}$ Piso, Col. Villa Quietud, Mexico, DF \\ ${ }^{3}$ Facultad de Medicina Veterinaria y Zootecnia, Universidad Nacional Autonoma de Mexico, \\ Ciudad Universitaria, Mexico DF \\ ${ }^{4}$ Unidad de Investigacion Medica en Inmunologia, Hospital de Pediatria, \\ Centro Medico Nacional Siglo XXI, Av. Cuauhtemoc 300, Col. Doctores, 03025, Mexico, DF
}

\begin{abstract}
In previous studies with a lectin from crotalid poison that was called Fraction AL27, its capacity to penetrate the cell was detected. It was considered that such an effect made fraction AL27 usable as a facilitating agent in the cell capture of plasmids transporting genes of interest. Therefore, it was evaluated if crotalid fraction AL27 by means of the pGFP reporter plasmid could favor transfection and plasmid expression in vitro and in vivo conditions. When, carrying out transfections under the calcium/phosphate system in CHO cells and observation by Confocal Microscope (CM), a higher level of fluorescence was detected in monostrata transfected with the pGFP/AL27 mix when compared to those inoculated with the pGFP alone. By Flow Cytometry (FC) quantification, transfection efficiency was $14 \%$ for the pGFP plasmid and $24.87 \%$ for the pGFP/AL27 mix. When carrying out transfections by inoculation of the tibial muscle of mice and observation by $\mathrm{CM}$, it was detected that doses of 50,100 and $150 \mu \mathrm{g}$ of pGFP generated a good transfection level. The minimum $50 \mu \mathrm{g}$ of DNA doses was selected and it was observed that when $1.062 \mu \mathrm{g} \mathrm{mL} \mathrm{L}^{-1}$ of AL27 was added, fluorescence was as intense or similar to that provided by the doses of $150 \mu \mathrm{g}$ of pGFP alone.
\end{abstract}

Key words: Plasmid, Agkistrodon piscivorus, crotalid poison, lectins, jellyfish protein, fluorescence

\section{INTRODUCTION}

DNA vaccines are formed with two main elements: the gene that codifies the protein in charge of stimulating the immune response towards the antigen of interest and an expression vector (plasmid) in which it is inserted. The above guarantees innocuousness of the biological product, since it no contains the infectious agent.

Benefits of the recently called 3rd generation vaccines include the induction of a wide range in the immune response in which the Main Histocompatibility Complex type I and II (MHC I and MHC II) is involved as well as a high neonatal immunization potential, longevity of the immune response and the lack of immunogenic response to the vector proper. Also, they are of easy and quick production, they do not require handling under a cold chain and it is feasible to expand its use by adding genes of a great variety of pathogens, generating thus polyvalent vaccines (van Drunen et al., 2001). The disadvantage of genetic vaccines is the low efficiency of cellular transfection in vivo and lack of capacity to capture free DNA by cells that present the antigens, deriving in an insufficient immunogenicity (Bos et al., 2004) thus, requiring a high amount of antigenic mass for immunization.

As probable solution, several researchers have employed agents that act as transporters or facilitators of the transfection process. Up to date, to improve DNA expression levels by the host cell, experiments have been carried out with diverse mechanisms and biological products such as: gene gun, electroporation, naked DNA micro-injection (Donnelly et al., 1997), cationic carriers (Bos et al., 2004), local anesthetics (Danko et al., 1994), lipids (Mumper et al., 1996) and some proteins extracted

Corresponding Author: Arcelia Alvarado Islas, Departamento de Epizootiologia del Centro Nacional de Investigaciones Disciplinarias en Microbiologia, Instituto Nacional de Investigaciones Forestales, Agricolas y Pecuarias, Sagarpa, Km 15.5, Carretera Mexico-Toluca, Col. Palo Alto, 05110, Mexico 
from serpent venom (Coney et al., 1994). In prior studies focused on the search for an antiviral agent (Alvarado et al., 2004), the task group isolated a protein with lectin activity from Agkistrodon piscivorus serpent venom, that was named Fraction AL27. In this study, it was observed that AL27 could be recognized by sialic acid receptors and transferred into the host cell.

There are no precedents on the use of lectins as transfection favoring agents. Nevertheless, it is known that type $\mathrm{C}$ lectins present in dendritic cells act as receptors for cell adhesion signaling pathogens or as mediators for pathogen union and internalization (Cambi et al., 2004). In the case of crotalid lectins, its use has been limited to the determination of blood groups taking advantage of their receptor cell carbohydrate adhesion effect and in this manner agglutinate red blood cells (Sharon and Lis, 1972). With such a background it would seem that AL27 crotalid fraction would be an attractive alternative to be used as carrier and/or transfection facilitator agent of genes of interest plasmid carriers. In this study, fraction AL27 was evaluated to see if it could favor cell transfection under in vitro and in vivo conditions using for this a reporter plasmid that expresses a green fluorescent protein extracted from a jellyfish.

\section{MATERIALS AND METHODS}

Plasmid: Dr. Alvaro Aguilar Setien of the Mexican Social Welfare Institute (Instituto Mexicano del Seguro Social) kindly donated the pGFP plasmid that was used. This plasmid has similar characteristics as the one originally constructed and reported by Okabe et al. (1997) and it consists of the insertion of the green fluorescent protein obtained from Aequorea victoria jellyfish (GFP) in pCAGGS plasmid (Delagrave et al., 1995; Heim et al., 1994). The pGFP was replicated in competent cells of Escherichia coli (E. coli) DH10B by culturing in Luria Bertani agar (Sigma, L3272) for 24-48 h and propagated for 12-16 h in Luria Bertani broth (Sigma, L3022) at a temperature of $37^{\circ} \mathrm{C}, \mathrm{pH} 7.0$, in a 5-L fermentation chamber (Applikon, Foster City CA) with constant 300 rpm stirring until a $0.5 \mathrm{OD}_{500}$ cell density is obtained. After this incubation period, the bacterial suspension was collected and centrifuged at $4500 \mathrm{rpm}, 4^{\circ} \mathrm{C}$ for $15^{\prime}$ to obtain the cells.

The plasmid was purified by a classical procedure of DNA liberation from cells by alkaline lysis (Batard et al., 2001) and RNA was eliminated using lysolectin as RNase. Chromosome DNA was separated from plasmid DNA by filtration and purification with an anionic exchange column (Quiagen, 12145). Obtained DNA concentration was determined by spectrophotometer at $260 \mathrm{~nm}$ wavelength (Lowrie and Whalen, 2000; Wilfinger et al., 1997) and its purity by electrophoresis in 1\% agar gel (Laemmli, 1970).
Crotalid fraction AL27: Lyophilized venom from Agkistrodon piscivorus was donated by Biologist Monica Salmeron, person in charge of the Herpetarium of the National Autonomous University of Mexico. Isolation of fraction AL27 was carried out by Reverse Phase High Pressure Liquid Chromatography (RP-HPLC) (Chloupek et al., 1994; Mancin et al., 1998). A C18 silica gel column was used for the process $(5 \mu, 4.6 \times 2.5 \mathrm{~mm}$, Beckman) with a $50 \mu \mathrm{L}$ injector. The venom was diluted with HPLC grade water (Sigma 27,073-3) to a $100 \mu \mathrm{g} \mathrm{m}^{-1}$ concentration and then filtered with a $0.22 \mu \mathrm{m}$ pore nylon membrane (Millipore, GSWP 04700). Solubilizing and separation of polypeptides was performed with $0.1 \%$ Trifluoracetic Acid (TFA) (Sigma, 09653) in HPLC grade water (Solvent A) and 0.1\% Acetonitrile (ACN) (Sigma, 27071-7) in TFA (Solvent B). Both solvents were degasified and stirred by vacuum with a $0.22 \mu \mathrm{m}$ pore $\mathrm{GV}$ filter (Millipore, GV WP 04700). Elusion curve had an initial proportion of $30 \%$ solvent $\mathrm{B}$ over solvent $\mathrm{A}$ and progressed until solvent $B$ reached $100 \%$ in a programmed time of $10 \mathrm{~min}$ and a flow range of $1 \mathrm{~mL} \mathrm{~min}^{-1}$. Adsorption capacity was measured at $280 \mathrm{~nm}$ wavelength. Diverse crotalid fractions (proteins and polypeptides) detected for chromatographic analysis were collected and concentrated by lyophilization. For use, they were re-suspended in $50 \mu \mathrm{L}$ of a $0.87 \%$ saline solution. Identification of fraction AL27 was carried out by chicken red blood cells hemagglutination tests and double dilutions of 1:2-1:128 with each one of the collected fractions (Gartner and Ogilvie, 1984).

Transfection in vitro: Chinese Hamster Ovary cells (CHO) were cultured (in vitro, LC18) in $25 \mathrm{~cm}^{2}$ Lab-Tek slides (Nunc, 163371 ), at $37^{\circ} \mathrm{C}$ for $20-24 \mathrm{~h}$ until $80 \%$ cell confluence was obtained. For this purpose a MEM Glasgow (in vitro, ME-054) culture medium was used, supplemented with 10\% bovine fetal serum (Sigma, F2442) and a mix of penicillin-streptomycin in a 1:100 proportion (in vitro, A-02). Three groups of slides were formed. In the first, cultures were transfected under the calciumphosphate system, adding pGFP plasmid in a proportion of $1 \mu \mathrm{g} \mathrm{mL}^{-1}$, mixed with a $\mathrm{CaCl}_{2} 2.4 \mathrm{M}$ suspension and 2X-HEPES buffered saline solution. The second group of slides were transfected in a similar manner but adding the AL27 fraction in a proportion of $1.062 \mu \mathrm{g} \mathrm{mL}^{-1}$. As control, the third group of slides only had the calcium-phosphate mix added without pGFP or AL27 (Sambrook and Russell, 2001).

Expression capacity of pGFP was determined under two systems: direct observation with the confocal microscope (qualitative) with a $488 \mathrm{~nm}$ laser light ray, previously fixing the transfected cultures with $80 \%$ 
acetone. Quantitative detection by flow cytometry (Bogh and Duling, 1993). For this purpose transfected monostrata were detached and the cells disaggregated with $0.25 \%$ trypsin-versene (in vitro, EN004) and suspended in $1 \mathrm{~mL}$ buffer PBS (PBS, $0.1 \%$ sodium azide, EDTA $5 \mathrm{mM}, 2 \%$ bovine fetal serum). For quantification, equipment was calibrated at $480 \mathrm{~nm}$ wavelength, under fluorescent light.

Transfection in vivo: Twenty, BALB/c, 3-4 weeks old, mice were used forming four groups with five animals each. In groups 1-3 the tibial muscle of each mouse was injected with $0.1 \mathrm{~mL}$ of pGFP plasmid, previously diluted in concentrations of 50,100 or $150, \mathrm{~g} \mathrm{~mL}^{-1}$, respectively. Group 4 remained as a negative control to which only $0.1 \mathrm{~mL}$ of sterile PBS (Helater, 2000) was administered. The animals were sacrificed 3 days after inoculation in order to determine the fluorescent green protein expression levels and the anterior tibial muscle was collected from each mouse. The tissue was adhered to a slide by pressure and fixed with $80 \%$ acetone. Tissues were observed by confocal microscope with a $488 \mathrm{~nm}$ laser light ray.

After determining the minimum pGFP doses to be used, a new group of mice $(n=5)$ were inoculated with the pGFP plasmid, adding $1.062 \mu \mathrm{g} \mathrm{mL} \mathrm{m}^{-1}$ of AL27. Animals were sacrificed 3 days after inoculation and their muscle tissues treated and observed.

\section{RESULTS AND DISCUSSION}

Figure 1 shows that the plasmid used in this study was replicated and purified in an efficient manner. DNA lots that were obtained varied from 959-1237 ng $\mu \mathrm{L}^{-1}$.

A. piscivorus venom chromatography showed that it is formed by 15 different proteins whose elusion times were $1.1,1.39,1.83,2.11,2.48,2.72,2.99,3.62,4.23,4.92$, $5.44,6.04,6.79,7.32$ and $8.28 \mathrm{~min}$, represented graphically by peaks (Fig. 2). Fraction AL27 is the twelfth eluded protein $(6.04 \mathrm{~min})$.

For each $100 \mu \mathrm{g}$ of processed poison, $17 \mu \mathrm{g}$ of AL27 were obtained. Purity of the isolation process and the non-alteration of the AL27 fraction structure were demonstrated by red cell corpuscle agglutination up to a level of 64 Hemagglutinating Units (HU), before and after the chromatographic process.

Images of Fig. 3 shows, the qualitative transfection and plasmid expression capacity of pGFP plasmid. Fluorescence intensity, represented by the annexed graphs, favors measuring of results as it detects higher amounts of flourescein in cells transfected with the pGFP/AL27 mix.

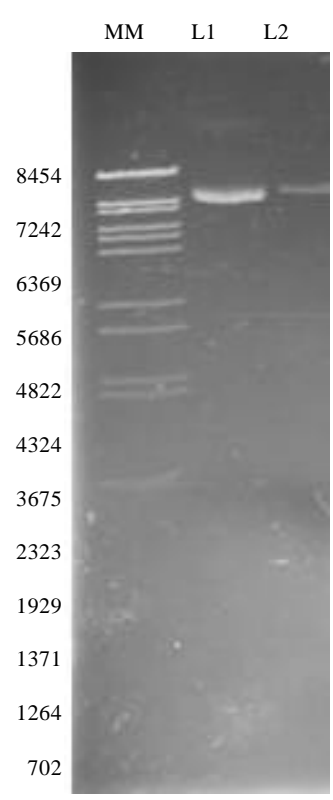

Fig. 1: Identification of pGFP degree of purity by electrophoresis in 1\% agar gel. MM, Molecular weight marker; L1, pGFP collected after going through the anionic exchange column; L2, pGFP collected after its precipitation. Both columns show a sole DNA band

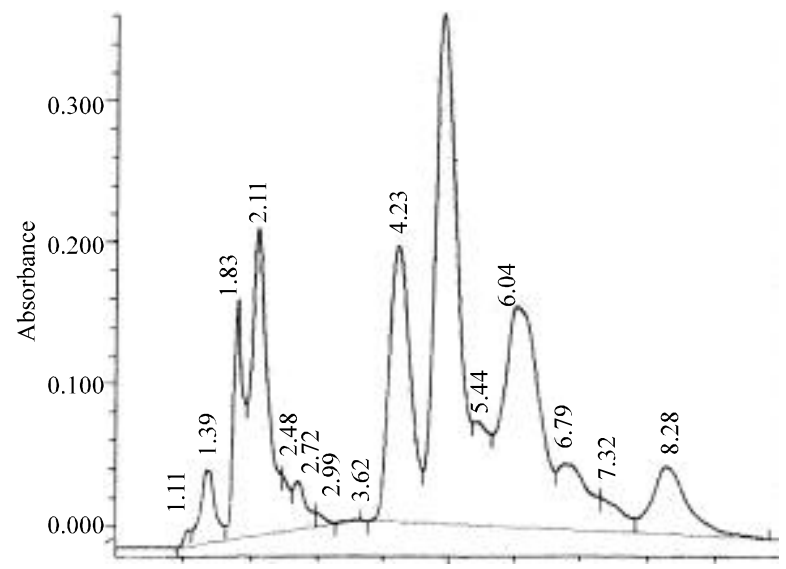

Fig. 2: Chromatographic pattern of Agkistrodon piscivorus serpent's venom obtained by HPLC$\mathrm{RP}$. Of the 15 peaks that correspond to different protein components of the venom, the number 12 with an elusion time of $6.04 \mathrm{~min}$, showed hemagglutinating activity

Transfection efficiency determined by flow cytometry was $3.24 \%$ with pGFP plasmid on its own and $7.32 \%$ when added with AL27 (Fig. 4). 

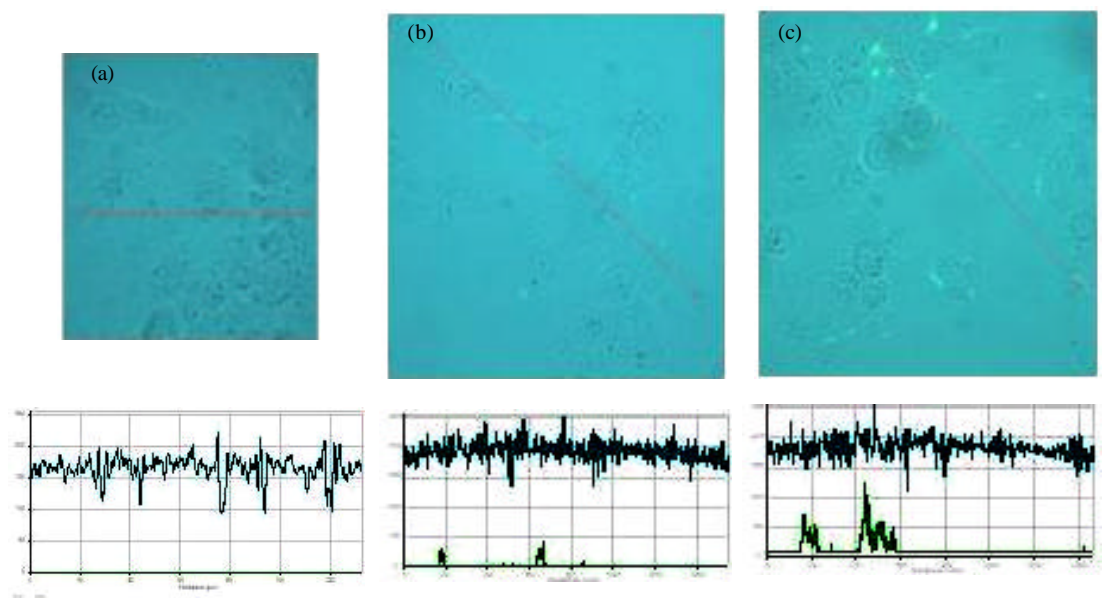

Fig. 3: In vitro expression of pGFP in CHO cells observed by Confocal Microscope (CM). (a) show negative control cells, inoculated with a mix of calcium/phosphate and free of fluorescence, (b) correspond to cells transfected with $1 \mu \mathrm{g} \mathrm{mL}^{-1}$ of pGFP and a value of fluorescence intensity close to 50 and (c) show cells transfected with $1 \mu \mathrm{g} \mathrm{mL}{ }^{-1}$ pGFP added with $1.062 \mu \mathrm{g} \mathrm{mL}{ }^{-1}$ of the AL27 fraction, with a larger expression area and a fluorescence intensity value close to 150
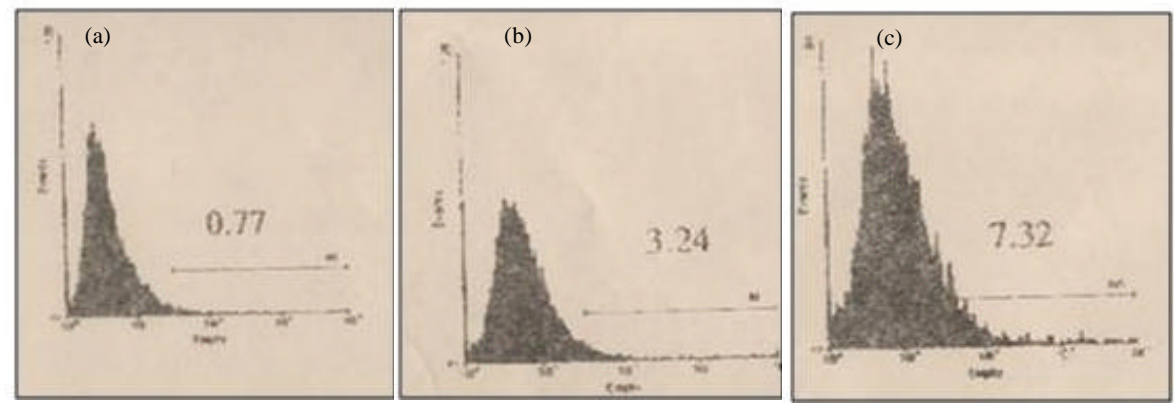

Fig. 4: In vitro expression of pGFP in $\mathrm{CHO}$ cells quantified by Flow Cytometry (FC). (a) Shows negative control cells, transfected with a mix of calcium//phosphate and free of fluorescence $(0.77 \%$ ), (b) Corresponds to cells modified with $0.1 \mu \mathrm{g} \mathrm{mL}{ }^{-1}$ of pGFP ( $3.24 \%$ transfection) and (c) shows cells modified by pGFP with AL 27 fraction added (7.32\% transfection)

A good level of transfection and expression was observed in all muscle tissues of mice inoculated with the different doses of pGFP. Therefore, the minimum dose of $50 \mu \mathrm{g}$ of pGFP was selected to evaluate the action of fraction AL27, finding that AL27 demonstrated higher efficiency, since doses of $50 \mu \mathrm{g}$ of DNA added with AL27, provided similar results as those given with 100 and $150 \mu \mathrm{g}$ of DNA.

According to the results that were obtain, the AL27 crotalid fraction demonstrated that it could favor levels of reporter pGFP capture by host cells. Its efficiency was determined by increments in flourescein observed qualitatively by Confocal Microscope (CM), under in vitro as well as in vivo conditions and likewise quantitatively by Flow Cytometry analysis (FC) (Fig. 5). There are no previous studies describing the use of crotalid lectins (in this case of the Agkistrodon piscivorus serpent's venom isolated fraction called AL27) as agents that favor or are carriers of DNA segments.

Nevertheless, it is known that lectins that are present in dendritic cells have the mission of detecting pathogenic agents and introducing them by means of the sialic acid receptors into the cell (Cambi et al., 2004). On the other hand, lectins isolated from plants (Concavalina A) are commonly used to determine blood groups due to their capacity of recognizing and capturing carbohydrates that are present in the cellular receptors of blood cells (Sharon and Lis, 1972). For this reason, it was considered 

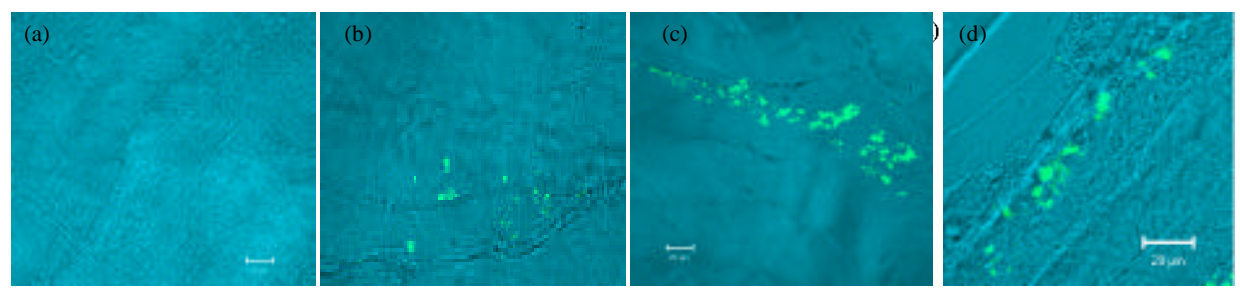

Fig. 5: In vivo transfection with pGFP in mice tibial muscles as observed by Confocal Microscope (CM). (a) shows negative control tissue, free of fluorescence, (b) is of a muscle inoculated with $50 \mu \mathrm{g}$ pGFP alone, (c) is muscle with $150 \mu \mathrm{g}$ pGFP alone and (d) belongs to muscle inoculated with $50 \mu \mathrm{g}$ of pGFP added with $1.062 \mu \mathrm{g}$ of the AL27 fraction. Figure $5 \mathrm{~d}$ shows that fluorescence was as intense or similar to that provided by the doses of $150 \mu \mathrm{g}$ of pGFP alone (Fig. 5c)

in this study that crotalid lectin could have a similar activity. The action mechanism was not elucidated, nevertheless its favorable effect on transfection and reporter plasmid expression was demonstrated as well as the lack of toxic effects or cell damage (Alvarado et al., 2004).

\section{CONCLUSION}

Therefore, it is considered that fraction AL27 could be a beneficial agent in the use of gene vaccines.

\section{REFERENCES}

Alvarado, I.A., V.O. de Paz, C.Y. Leon and S.A. Aguilar, 2004. Purification of a hemagglutinant fraction from crotalid venom: in vitro and in vivo evaluation of cell damage. Tec. Pecu. Mex., 42: 247-260.

Batard, P., M. Jordan and F. Wurm, 2001. Transfer of high copy number plasmid into mammalian cells by calcium phosphate transfection. Gene, 270: 61-68.

Bogh, L.D. and T.A. Duling, 1993. Flow cytometry instrumentation in research and clinical laboratories. Clin. Lab. Sci., 6: 167-173.

Bos, G.W., T. Kanellos, D.J.A. Crommelin, W.E. Hennink and C.R. Howard, 2004. Cationic polymers that enhance the performance of HbsAg DNA in vivo. Vaccine, 23: 460-469.

Cambi, A., F. de Langue, N. van Maarseveen, M. Nijhuis and B. Joosten et al., 2004. Microdomains of the C-type lectin DC-SIGN are portals for virus entry into dendritic cells. J. Cell. Biol., 164: 145-155.

Chloupek, R.C., W.S. Hancock, B.A. Marchylo, J.J. Kirkland, B.E. Boves and L.R. Snyder, 1994. Temperature as a variable in reverse-phase highperformance liquid chromatographic separations of peptide and protein samples. II. Selectivity effects observed in the separation of several peptide and protein mixtures. J. Cromatogr. A., 686: 45-59.
Coney, L., B. Wang, K.E. Ugen, J. Boyer and D. McCallus et al., 1994. Facilitated DNA inoculation induces anti-HIV-1 immunity in vivo. Vaccine, 12: $1545-1550$

Danko, I., J.D. Fritz, S. Jiao K. Hogan, J.S. Latendresse and J.A. Wolff, 1994. Pharmacological enhancement of in vivo foreign gene expression in muscle. Gene. Ther., 1: 114-121.

Delagrave, S., R.E. Hawtin, C.M. Silva, M.M. Yang and D.C. Youvan, 1995. Red-shifted excitation mutants of the green fluorescent protein. Nat. Biotechnol., 13: $151-154$.

Donnelly, J.J., J.B. Ulmer, J.W. Shiver and M.A. Liu, 1997. DNA vaccines. Annu. Rev. Immunol., 15: 617-648.

Gartner, T.K. and M.L. Ogilvie, 1984. Isolation and characterization of three $\mathrm{Ca} 2+$-dependent betagalactoside-specific lectins from snake venoms. Biochem. J., 224: 301-307.

Heim, R., D.C. Prasher and R.Y. Tsien, 1994. Wavelength mutations and posttranslational autoxidation of green fluorescent protein. Proc. Natl. Acad. Sci. USA., 91: 12501-12504.

Helater, L.D., 2000. Intramuscular and intradermal injection of DNA Vaccines in mice and primates. Methods molecular med., 29: 71-77.

Laemmli, U.K., 1970. Cleavage of structural proteins during the assembly of head of bacteriophage $\mathrm{T}_{4}$. Nature, 227: 680-685.

Lowrie, D.B. and R.G. Whalen, 2000. DNA Vaccines: Methods and Protocols. 2nd Edn., Humana Press, Totowa, NewJersey, pp: 384.

Mancin, A.C., A.M. Soares, S.H. Andriao-Escarso, V.M. Faca and L.J. Greene et al., 1998. The analgesic activity of crotamine, a neurotoxin from Crotalus durissus terrificus (South American rattlesnake) venom: A biochemical and pharmacological study. Toxicon., 36: 1927-1937. 
Mumper, R.J., J.D. Duguid, K. Anwer, M.K. Barron, H. Nitta and A.P. Rolland, 1996. Polyvinyl derivates as novel interactive polymers for controlled gene delivery to muscle. Pharm. Res., 13: 701-709.

Okabe, M., M. Ikawa, K. Kominami, T. Nakanishi and Y. Nishimune, 1997. Green mice as a source of ubiquitous green cells. FEBS. Lett., 407: 313-319.

Sambrook, J. and D.W. Russell, 2001. Molecular Cloning. A Laboratory Manual. 3rd Edn., Cold Spring Harbor Laboratory Press, Cold Spring Harbor, New York, ISBN: 0879695773 , pp: 2100.
Sharon, N. and H. Lis, 1972. Lectins: Cell-agglutinating and sugar-specific proteins. Science, 177: 949-959.

Van Drunen, L.H.S., B.I. Loher and L.A. Babiuk, 2001. Immunization of livestock with DNA vaccines: Current studies and future prospects. Vaccine, 19: 2474-2479.

Wilfinger, W.W., K. Mackey and P. Chomczynski, 1997. Effect of $\mathrm{pH}$ and ionic strength on the spectophotometric assessment of nucleic acid purification. Biotechniques, 22: 474-476-478-481. 